\title{
PERCEPÇÕES SOBRE AS PARALIMPÍADAS ESCOLARES: UM ESTUDO COM ATLETAS
}

\author{
Mariana Corrêa de Resende \\ Universidade Federal de São João del Rei, São João del Rei, Minas Gerais, Brasil. \\ Maria Nivalda de Carvalho-Freitas \\ Universidade Federal de São João del Rei, São João del Rei, Minas Gerais, Brasil. \\ Andréa Carmen Guimarães \\ Universidade Federal de São João del Rei, São João del Rei, Minas Gerais, Brasil.
}

\begin{abstract}
Resumo
O paradesporto no Brasil vem se fomentando devido a um conjunto de motivos, como o fato de termos sediado as Paralimpíadas Mundiais 2016, maior interesse do público/mídia, aumento no número de adeptos das modalidades e construção do centro de treinamento. Além disso, o legado deixado pelo evento se constituiu também no aumento das expectativas de todos os envolvidos nesse movimento. Sendo assim, buscou-se analisar as expectativas de paratletas em nível escolar. Entrevistou-se 114 atletas brasileiros de ambos os sexos, com idade média de $\pm 15,45$ anos, participantes das Paralimpíadas Escolares. Identificou-se a relevância da participação nessa competição na modificação da percepção dos jovens em relação aos seus projetos futuros e a oportunidade de serem valorizados e vistos com orgulho pelo meio social.
\end{abstract}

Palavras-chave: Esporte Paralímpico. Paralimpíadas Escolares. Atleta. Expectativa.

\section{PERCEPTIONS ON SCHOOL PARALYPICS: A STUDY WITH ATHLETES}

\begin{abstract}
The paradesport in Brazil is being promoted due to a number of reasons, such as the fact that we have hosted the World Paralympics, greater public/media interest, increase in the number of fans of the modalities and construction of the training center. In addition, the legacy left is also an increase in the expectations of all those involved in this movement. Thus, we sought to analyze the expectations of paratletas at school level. We interviewed 114 Brazilian athletes, of both sexes, of age \pm 15.45 years, participating in School Paralympic Games. It was identified the relevance of participation in this competition in the modification of the perception in relation to future projects and as an opportunity to be seen as an object of valorization and pride in the social environment.
\end{abstract}

Keywords: Paralympic Sport. School Paralympics. Athlete. Expectation 


\title{
PERCEPCIONES ACERCA DE LAS PARALIMPIADAS ESCOLARES: UN ESTUDIO CON ATLETAS
}

\begin{abstract}
Resumen
El paradesporto en Brasil se viene fomentando debido diversos motivos, como el hecho de tener ubicadas las Paralimpíadas Mundiales 2016, mayor interés del público/imprenta, mayor número de adeptos de modalidades y construcción del centro de entrenamiento. Además, el legado dejado se constituye también en el aumento de expectativas de todos involucrados en el movimiento. Siendo así, se buscó analizar las expectativas de paratletas a nivel escolar. Entrevistó 114 atletas brasileños, de ambos sexos, de edad $\pm 15,45$ años, participantes de las Paralimpíadas Escolares. Se identificó la relevancia de la participación en esta competición en la modificación de la percepción de los proyectos futuros y como oportunidad de ser vistos como objeto de valorización y orgullo por el medio social.Palabras clave: Deporte Paralímpico. Paralímpíadas Escolares. Atleta. Expectativa
\end{abstract}

\section{Introdução}

O paradesporto vem se destacando no mundo, conquistando vários adeptos, aumentando o número de competições e modalidades esportivas, além de propiciar o surgimento de novas metodologias e técnicas de treinamento (CARDOSO, 2016). Outro aspecto importante que o mesmo autor revela, é o fato de despertar o interesse científico, cada vez mais presente nos últimos anos. Tudo isto, tem contribuído para o fomento do esporte paralímpico ${ }^{1}$ em todos os níveis.

O Brasil também acompanha esse processo de ascensão, apresentando bons resultados como o sétimo lugar nos Jogos Paralímpicos de Londres de 2012 e oitavo nos Jogos Paralímpicos do Rio de Janeiro em 2016, além da liderança por três edições consecutivas nos Jogos Para-Panamericanos, nos anos de 2007, 2011 e 2015, que representam a principal competição das Américas (HAIACHI et al., 2016). Além disso, esse aumento significativo se deve à era da inclusão e também pela maior divulgação do esporte paralímpico pelas mídias (VILLAS BOAS; BIM; BARIAN, 2003).

Esse cenário pode vir a representar o ponto de partida para transformar espectadores em novos atletas e permitir o surgimento de fãs do esporte adaptado no país. Ou seja, tornarse fonte de inspiração para aqueles que, hoje, iniciam a prática (HAIACHI et al., 2016).

Segundo Costa e Winckler (2012), o esporte paralímpico ou o paradesporto, está condicionado a um ambiente mais restrito, que envolve apenas as modalidades oficiais incluídas nos Jogos Paralímpicos, sendo acessível somente àqueles que são elegíveis de acordo com as regras de classificação funcional. Enquanto o esporte adaptado possui um universo mais abrangente que engloba várias atividades esportivas adaptadas para pessoas com algum tipo de deficiência, desde que sejam realizadas as adequações e transformações necessárias.

Atualmente, com a crescente participação da pessoa com deficiência (PcD) nas atividades esportivas, entidades e associações foram criadas com o intuito de estimular a prática desde iniciação até o alto rendimento, organizando competições regionais, nacionais e até mesmo as internacionais. Além disto, é importante destacar o avanço da educação física

\footnotetext{
${ }^{1}$ A partir de novembro de 2011, o termo correto é paralímpico e não paraolímpico, tanto com referência ao esporte quanto ao órgão administrador que é o Comitê Paralímpico Brasileiro (CPB). Essa mudança foi necessária para que houvesse alinhamento com a terminologia dos demais países de língua portuguesa e para que não houvesse conflito com a terminologia do movimento olímpico (MELLO E WINCKLER, 2012).
} 
adaptada no que se refere às práticas esportivas por parte da $\mathrm{PcD}$, e suas possíveis contribuições na vida desses sujeitos (DA COSTA; SOUSA, 2004).

Por essa razão é importante se investir nos níveis escolares, sendo essa a maior porta de entrada para a formação de paratletas de alto rendimento. As Paralimpíadas Escolares são um bom exemplo disso. É considerada a maior competição em nível escolar nacional e reconhecida como um celeiro de novos talentos, podendo destacar nomes importantes do esporte paraolímpico de mais alto nível, como Alan Fonteles, Lorena Spoladore e Verônica Hipólito, que começaram dessa forma (CARDOSO, 2016; CPB, 2015; PORTAL BRASIL, 2016).

Além disso, Cardoso (2016) complementa afirmando que a profissionalização conquistada por atletas como esses inspira e estimula a formação de futuros campeões. Uma nova geração que se espelha em seus exemplos e está ansiosa para fazer parte dessa parcela de atletas paralímpicos que chegaram ao alto rendimento.

Tendo esse contexto como referência, torna-se necessário ouvir esses atletas, que participam das paralimpíadas escolares, visando identificar os motivos que têm levado alunos com deficiência a aderir à prática esportiva e suas expectativas em relação ao futuro. Assim, este estudo pretende agregar-se a outros que têm buscado conhecer as necessidades, perspectivas e motivações de atletas paralímpicos para as práticas paradesportivas, visando um maior conhecimento dessa realidade no país para o desenvolvimento de novos talentos.

Um estudo realizado por Silva (2016), por exemplo, buscou investigar o perfil de pessoas com deficiência que iniciaram a prática de vôlei sentado e basquete em cadeira de rodas em Goiânia. Foi identificado que os motivos que levaram as pessoas com deficiência a procurarem o esporte adaptado foram a superação dos limites e a vontade de praticar uma atividade física. Já os motivos pelos quais elas permaneceram foram a saúde, reabilitação e o desejo de competir. Também foi verificado que a prática do paradesporto auxilia no estabelecimento de relações sociais, possibilitando maior inclusão. Ademais, foi constatado que familiares e amigos próximos possuem alto poder de influência sobre esses atletas e a classe econômica a que pertencem também tem impacto na sua trajetória esportiva. Os pontos negativos encontrados foram o contato com apenas uma modalidade paradesportiva, a falta de políticas públicas e a inacessibilidade. Como benefícios, destacaram-se melhorias no repertorio motor, maior autonomia e qualidade de vida.

Tendo em vista todos esses aspectos supracitados, o objetivo deste estudo foi analisar as percepções de atletas em nível escolar dentro do esporte paralímpico e identificar suas projeções em relação ao futuro.

\section{Metodologia}

\section{Aspectos éticos}

Foram seguidas as normas da Resolução $n^{\circ} .466$ de 2012 do Conselho Nacional de Saúde. O desenvolvimento desta pesquisa obteve o consentimento dos responsáveis legais pelas instituições e dos próprios participantes, após aprovação pela Comissão de Ética em Pesquisa Envolvendo Seres Humanos. Este estudo deriva-se de um projeto maior denominado Promoção de Saúde e suas Interfaces Físicas e Psicológicas: programa de intervenção e pesquisa com idosos, pessoas com deficiência, adultos com diabetes e hipertensos.

\section{Participantes}

Os sujeitos da pesquisa foram atletas escolares participantes do maior evento paradesportivo escolar em nível nacional. O critério para escolha dos participantes foi de 
conveniência, considerando a disponibilidade e consentimento dos atletas e dos técnicos durante a realização das Paralimpíadas Escolares.

Sendo assim, participaram 114 atletas de paradesporto em nível escolar, 82 com deficiência física e 32 com deficiência visual, sendo 24 de modalidades coletivas e 90 de modalidades individuais (atletismo, futebol de 7, goalball, judô, natação, tênis de mesa, tênis em cadeira de rodas), de ambos os sexos, com idade média de 15,45 anos $( \pm 1,44)$, de escolas públicas e privadas, de 21 estados do Brasil, representantes de todas as cinco regiões.

Foram realizadas entrevistas semiestruturadas com os atletas. Após Consentimento e Assentimento Livre e Esclarecido, os atletas responderam às questões que versavam sobre as expectativas que tinham em relação ao esporte paralímpico, possíveis perspectivas de desenvolvimento no esporte e motivos para a prática esportiva.

\section{Procedimento}

Primeiramente, foi solicitado à Academia Paralímpica do Comitê Paralímpico Brasileiro uma autorização para realização do estudo no evento Paralimpíadas Escolares. Posteriormente, apresentou-se a pesquisa aos técnicos e atletas, após aceitação, os técnicos assinaram o Termo de Consentimento Livre e Esclarecido (TCLE), e os atletas, um Termo de Assentimento Livre e Esclarecido (TALE), concordando em participar voluntariamente da pesquisa.

Logo após esse processo inicial, os atletas responderam a uma anamnese com o intuito de caracterizá-los sócio e demograficamente e em relação à formação esportiva. E por fim, gravou-se a entrevista semiestruturada que posteriormente foi transcrita para análise.

\section{Análise de dados}

Para análise de dados sociodemográficos e de formação esportiva, recorreu-se a estatística descritiva, indicando frequência média e desvio padrão.

Quanto à entrevista semiestruturada, transcreveu-se e utilizou-se a técnica metodológica denominada Análise do Conteúdo proposta por Bardin (2009). Segundo esse autor, são necessários alguns procedimentos para análise de conteúdo como: "leitura flutuante" das questões, agrupamento e classificação das questões segundo a frequência percentual de respostas similares, "exploração exaustiva" e a identificação de relações realizadas pelos respondentes.

\section{Resultados e discussões}

A partir das análises realizadas, as respostas dos atletas que participaram da pesquisa foram agrupadas em categorias. As categorias de análise foram: a) Motivação para a participação nas paralimpíadas escolares e b) Expectativa em relação ao futuro no esporte.

\section{Motivação para a participação nas paralimpíadas escolares}

Em relação à motivação dos atletas para a participação nas paralimpíadas escolares foram identificadas seis principais categorias. A primeira delas denomina-se "Curiosidade/Experienciar" que está relacionada à vontade de conhecer e viver a sensação de estar em uma competição grande; a segunda, chamada "Sonho", refere-se ao sonho de ser um grande atleta, a busca pelo profissionalismo e por uma vida melhor a partir do esporte; a terceira categoria "Gostar de esportes/Competições/Prazer" que se entende pela paixão pelo esporte, pelo prazer em praticar as modalidades e por estar em competições. A categoria 
seguinte, a quarta, "Esforço próprio/Superação", refere-se à própria capacidade de ter conquistado tudo que conquistou no esporte até aquele momento para estar ali, representando seu estado. Na quinta categoria "Professor/Família", o atleta reconhece o apoio de professores/treinadores e da família como responsáveis pela sua participação nas paralimpíadas escolares; e por fim, a sexta, chamada "Vida Saudável/Qualidade de Vida", relaciona-se ao estilo de vida adotado por eles que, consequentemente, os levaram a estar lá.

Tabela 1 - Categorização das respostas relacionadas à Motivação para a participação nas paralimpíadas escolares

\begin{tabular}{lc}
\hline \multicolumn{1}{c}{ Categorias } & $\mathbf{\%}$ \\
\hline Curiosidade/Experienciar & $5 \%$ \\
Sonho & $12 \%$ \\
Gostar de Esportes/competições/Prazer & $\mathbf{2 8 \%}$ \\
Esforço Próprio/Superação & $23 \%$ \\
Professor/Família & $14 \%$ \\
Vida Saudável/Qualidade de Vida & $8 \%$ \\
Sem resposta & $10 \%$ \\
\hline
\end{tabular}

Em relação aos motivos que os trouxeram às paralimpíadas escolares, $28 \%$ afirmaram ser pelo amor ao esporte e pelo sentimento de prazer em praticar e competir, assim como mostram os discursos dos seguintes atletas, Sujeito 23: "Prazer mesmo, eu faço isso por prazer, eu... eu sempre gostei de esporte, eu faço isso por puro prazer."; Sujeito 73: "Amor ao futebol"; Sujeito 5 reforça a ideia, acrescentando também o desejo de estar no Ranking mundial:

S5: Porque eu amo a modalidade que faço, quero estar no Ranking mundial, e é por isso que eu vim aqui." e do Sujeito 78 "Motivos. Como eu falei, a conquista. A conquista pra mim é uma coisa que me deixa bastante animado, (vou na) competição meu foco é só no meu tempo, no meu objetivo. Meu objetivo qual é? Ir pro Parapan cara. Depois do Parapan, eh... seguir pela frente.

Cardoso, Palma e Zanella (2010) afirmam que a competitividade é o fator que mais motiva em uma prática esportiva. Já para Balbinotti et al. (2012) o prazer é a dimensão mais motivadora para os atletas que buscam por vontade própria o esporte, com o intuito de conhecê-lo e explorá-lo de acordo com seus interesses pessoais. O contrário também ocorre, ou seja, aqueles que não sentem prazer ao praticar determinado esporte têm mais chances de abandoná-lo precocemente. Em outro estudo, Balbinotti e Capazzole (2008) declaram que os principais motivos estimuladores da prática esportiva são: vontade própria, prazer, satisfação e interesse em conhecer e explorar seus conhecimentos sobre determinada modalidade. Segundo Sampedro (2012) para se obter prazer em uma atividade esportiva, o sujeito deve ter interesse pela sua prática, podendo ser movido a agir por divertimento, por vontade ou por algum desafio que ache relevante.

O segundo motivo mais escolhido pelos entrevistados, com $23 \%$ da amostra, foi o esforço próprio ou superação de limites, em que eles expressam sua vontade de ser cada dia melhores, derrubando paradigmas e mostrando suas capacidades. Isto fica claro nas falas seguintes. Sujeito 3: "O meu esforço na natação, que estou cada vez me entregando, cada dia mais em busca do meu sonho."; Sujeito 31: "Acho que antes de tudo esforço próprio, é superação, força de vontade. E depois... ai, encontrar pessoas com quem... que fizeram com que eu evoluísse pra tá numa competição desse nível.”; Sujeito 4: "Motivação. Saber que eu consigo fazer, ter força e me superar"; Sujeito 84: "A força de vontade de quebrar cada vez 
mais barreiras.”, Sujeito 65: “As pessoas falaram que eu não era capaz.”; e também no discurso do Sujeito 32:

S32: A motivação, a superação, a vontade de vencer $e$ quando a gente tem motivação, quando a gente se supera, quando a gente tem muita vontade de vencer a gente tenta, por mais que uma vez dê errado ou outra, mas sempre vai dar certo, uma hora vai dar certo e é por isso que hoje eu tô aqui onde eu estou, por muito treinamento, por tudo.

Como pode se pode observar nos discursos dos jovens a vontade de superar limites e de se superar é evidente. Estudiosos como Brazuna e Castro (2001), comentam que no esporte adaptado isto é muito comum, que desperta em seus atletas um sentimento de competição consigo mesmo e contra sua deficiência. Tal superação contribui para a melhoria de elementos como a autoestima, por exemplo, devido ao reconhecimento de suas próprias capacidades, além de despertar o reconhecimento externo como atleta e indivíduo.

O terceiro motivo mais expressado (14\%) foi em relação ao apoio da família, dos técnicos e treinadores para que eles estejam competindo nas paralimpíadas escolares. Conforme o Sujeito 22: "Minha mãe, pela minha mãe que eu to fazendo isso.", o Sujeito 56: "Ah, porque eu gosto e porque minha família toda joga futebol.", e também o Sujeito 67:

S67: Acho que o que motiva, acho que os principais motivos. Acho que é pra minha família né? Que aí minha mãe dá pra vê... eu vejo a felicidade que ela me vê competindo, meus familiar o orgulho que eles têm. Eu acho que isso é um dos principais motivos pra eu estar aqui.

Segundo Palla (2001), a motivação para iniciar e permanecer no esporte depende e muito do apoio familiar. Por outro lado, verifica-se, nas respostas, a importância da valorização da família em relação ao esporte e à participação deles nas paralimpíadas como uma concretização de desejos familiares em que eles se tornam motivo de orgulho. Esse resultado indica a importância do esporte paralímpico na modificação da percepção da pessoa com deficiência sobre si mesma, de uma identidade deteriorada (Goffman, 1982) para um motivo de orgulho pessoal e para a família. Esse resultado abre novas possibilidades de investigação sobre o papel das paralimpíadas na reconfiguração identitária de pessoas com deficiência e de seus familiares. Além da família, os técnicos também são vistos como tendo um papel importante para a participação deles nas paralimpíadas escolares.

O Sujeito 87 destaca o papel do treinador: "O que me trouxe até aqui foi acho que o incentivo do meu técnico, da... minha técnica". Essa constatação indica a importância desse profissional para os atletas, como também é explicitado por Barreto (2008), ao reforçar o papel dos treinadores em investir na persistência e estimular o envolvimento dos atletas nas tarefas do esporte.

O quarto motivo destacado por eles foi a busca da realização de grandes sonhos, representando $12 \%$ da população estudada, como ser um atleta reconhecido e participar de grandes eventos esportivos. Sendo assim, sabe-se que a iniciação para se tornar um grande atleta, começa em competições escolares como essas. Sujeito 8: "Meu desejo, ser jogador de futebol profissional." e também o Sujeito 42: "Os meus motivos é porque em primeiro lugar sempre tive um sonho de participar das Paralimpíadas Escolares, então eu me esforcei e com a ajuda de Deus até hoje eu cheguei aqui.”. Brazuna e Castro (2001) acreditam que o empenho na carreira esportiva é tão intenso que as rotinas pessoal e profissional acabam se aliando às metas dentro do esporte, dessa forma, muitos atletas se definem a partir do esporte e do sentido que ele traz para suas vidas.

A busca pela vida saudável e qualidade de vida, também foi considerado um dos motivos (8\%), como vemos nas falas do Sujeito 9: "Porque eu po... porque eu queria mudar, 
queria ser diferente, queria poder correr muito, poder me exercitar bastante, ficar mais forte. É isso."; do Sujeito 14: "O que me trouxe até aqui foi uma oportunidade que eu vi que posso começar um sonho que desejo realizar. Meu motivo é ser campeão.”; e também do Sujeito 36: "Primeiro motivo é por causa da deficiência do meu braço, porque quando eu nasci aí o médico me... me disse pra mim fazer pra mim melhorar o meu desempenho. E Porque eu gosto muito também."

Itani (2004), afirma que o esporte adaptado traz benefícios fisiológicos na vida de seus praticantes, porém o principal benefício percebido por ele é o relacionado à autoestima, diminuindo assim riscos de quadros depressivos. O esporte adaptado, além de ser utilizado em processos de reabilitação das pessoas com deficiências, também proporciona benefícios à saúde, além de promover a integração social (TEODORO, 2006).

E, por fim, $5 \%$ dos atletas afirmaram que o que os levaram às paralimpíadas escolares foi o sentimento de curiosidade e também a vontade de experienciar uma competição dessa dimensão. O Sujeito 19 expressa a curiosidade em conhecer a modalidade e uma competição: "Ah, eu vi o povo fazendo, entrei pra vê se era bom, gostei e agora to aqui.", já os Sujeito 27 e Sujeito 107, expressam respectivamente, a vontade de experienciar aqueles momentos: "Então, nessa competição? Nessa competição mais uma experiência né? Mais uma... assim, um aprendizado né? Um aprendizado assim, tanto da prova quanto experiência assim, em relação a tudo né? Uma experiência e... sei lá."; "Pra me ajudar e ganhar experiência pra... pra mim chegar na Paraolimpíadas.”.

\section{Expectativa em relação ao futuro no esporte}

Em relação às suas expectativas para o futuro dentro do esporte, como pode ser visto na Tabela 2, as respostas não se diferiram da dinâmica da primeira e, a partir da análise de conteúdo, foram identificadas cinco categorias. A primeira, denominada "Paralimpíadas Mundiais" demonstra o desejo de participar das próximas edições da Paralimpíadas e representar o Brasil; a segunda, chamada "Reconhecimento, Fama e Prêmios", refere-se a uma motivação extrínseca na qual se almeja o reconhecimento mundial pelas suas conquistas, interação com a mídia, construção de uma reputação dentro do esporte e a aquisição de prêmios, troféus e medalhas. A terceira delas, "Vida Saudável", revela a busca de uma vida saudável a partir do esporte; a quarta categoria presente, é a "Superação de limites", que se baseia na superação de todas as dificuldades encontradas ao longo da vida, querer superar suas próprias expectativas e as dos demais, mostrando sua capacidade de realizar tudo que se deseje ou sonhe. E finalmente, a quinta e última, "Conhecer pessoas e lugares", que expressa a vontade de viajar, em virtude do esporte, e conhecer lugares e pessoas do mundo todo.

Tabela 2 - Categorização das respostas relacionadas à Expectativa em relação ao futuro no esporte

\begin{tabular}{lc}
\hline \multicolumn{1}{c}{ Categorias } & \% \\
\hline Conhecer Pessoas e Lugares & $6 \%$ \\
Superação de Limites & $2 \%$ \\
Vida Saudável & $3 \%$ \\
Reconhecimento, Fama e Prêmios & $\mathbf{4 8 \%}$ \\
Paralimpíadas Mundiais & $33 \%$ \\
Sem resposta & $8 \%$ \\
\hline
\end{tabular}


Como visto acima, 33\% dos entrevistados desejam participar de alguma Paralimpíadas representando o Brasil, alguns ainda especificam seu desejo a curto prazo como, por exemplo, estar nas Paralimpíadas de 2020 em Tóquio, como expressa o Sujeito 94: "Espero alcançar todos os meus objetivos, que no meu grande sonho é Paralimpíadas de Tóquio 2020, e agora conseguir melhora de tempos, assim pra melhorar cada vez mais" e o Sujeito 90: "Eu desejo ser campeã mundial, desejo entrar na Paralimpíadas de 2020, desejo que eu consiga levar minha carreira profissional, que eu consiga me sustentar no esporte. Acho que é isso."

Benfica (2012) acredita que a profissionalização e a possibilidade de ascensão podem tornar a prática paradesportiva mais atraente aos olhos de seus praticantes. Além disso, a trajetória rumo ao lugar mais alto do pódio pode contribuir para o crescimento tanto profissional como pessoal dos atletas.

Sujeito 32, também expressa suas expectativas quanto a Tóquio:

S32: Ah, de início é chegar a uma seleção como a gente já chegou e agora se manter, se manter lá na seleção e, se Deus quiser, tá em Tóquio 2020, tá nos mundiais aí e ser campeão do mundo e paralímpico pela seleção.

$48 \%$ dos respondentes têm a intenção de no futuro, tornarem-se pessoas reconhecidas no esporte paralímpico, conquistar fama, muitos prêmios e medalhas, como o Sujeito 105 que afirma: "Ser um grande jogador de tênis de mesa, reconhecido no Brasil e mundialmente. Os meus desejos são esses.". Sujeito 31 também almeja reconhecimento e títulos como pode ser observado em seu discurso: "Espero ser bem-sucedido, ganhar títulos, conseguir chegar numa seleção, conseguir ganhar as competições que a gente disputa e sempre tentar buscar evoluir e me tornar o melhor atleta possível.".

Tendo em vista tais resultados, pode-se destacar um estudo de Samulski e Noce (2002), no qual analisaram a motivação de 64 atletas de alto nível no esporte paralímpico de modalidades distintas e verificou-se que os principais motivos que os levavam a praticar esporte foram: "Ser Campeão", seguido de "Conquistar Medalhas" e, por fim, "Ser Reconhecido". Isso pode ser ilustrado também pela fala do Sujeito 91: "Ãhn... crescer como atleta, ganhando medalhas, competições e... é isso, me realizar no esporte. Eu espero chegar muito longe, conquistar o que eu preciso conquistar. E é isso.”.

Apenas $6 \%$, esperam que a partir do esporte possam conhecer pessoas e lugares novos, ou seja, estabelecer laços de amizades e conhecer o Brasil ou outros países, como retrata o Sujeito 93: "Eu? Quero viajar pelo mundo jogando tênis de mesa, conhecendo pessoas, novas amizades, mostrar que eu posso ser o melhor pra certas pessoas no caso.", e também o Sujeito 9: "Ganhar muitas medalhas e... e viajar bastante. E conhecer gente nova.".

Weinberg e Gould (2008) acreditam que uma das principais motivações para a prática esportiva para crianças é a questão das relações sociais. Eles ainda completam, afirmando que quando crianças e jovens participam de programas esportivos, têm a possibilidade de, além de encontrar seus velhos amigos, também fazer novas amizades e construir novas relações sociais. A questão da sociabilidade estimula as pessoas (sejam elas, crianças, jovens ou adultas) a praticarem atividades físicas (SAMPEDRO, 2012).

Saito (2007) em sua pesquisa analisou 32 atletas com deficiência visual, praticantes de modalidades coletivas, com o intuito de verificar o que motivava a prática esportiva. Observou-se que os motivos mais prevalentes foram a realização pessoal, a possibilidade de realizar trabalhos em equipe, saúde, melhoria de habilidade/capacidades e, por fim, encontrar com os amigos.

Em relação à categoria Vida saudável 3\% dos indivíduos afirmam que desejam uma vida mais saudável e ativa através do esporte, assim como se pode observar nas falas do Sujeito 113: "Ah, continuar mantendo a forma física e interação social.”; Sujeito 74: "Ah, eu espero sempre me manter em forma pra poder jogar e continuar jogando. Ah, não sei, eu 
pretendo primeiro ser feliz, ter amigos, ter saúde. Acho que é mais isso."; e também do Sujeito 45

\begin{abstract}
S45: Sim, a minha... o meu principal objetivo não é ser campeão de .. ser campeão, ir a uma Olimpíada. Claro que se surgir uma oportunidade, claro que eu vou gostar, né? Mas a minha principal... agora atualmente é manter saúde, ficar em forma, essas coisas assim.
\end{abstract}

Florence (2009) explica que a adoção de uma vida saudável e ativa proporciona melhores condições de saúde aos paratletas, porque os esportes e atividades físicas possibilitam crescimento, desenvolvimento motor, físico, emocional e social aos seus praticantes. Tal aderência promove experiências motoras mais amplas, visando uma melhoria na qualidade de vida.

No que diz respeito à categoria Superação de limites, $2 \%$ da amostra destacou que seu maior desejo era sempre a superação, com isto, entende-se como superar-se, superar obstáculos e limites ou até mesmo superar as expectativas de terceiros. Como vemos nas frases dos indivíduos a seguir, Sujeito 111: "Assim, o que eu penso é conseguir fazendo o melhor de mim, ne?!"; Sujeito 84: "Espero cada vez mais superar meus limites e ir para seleção nacional."; Sujeito 4: "Me superar a cada dia mais e saber que eu consigo."; e Sujeito 6: "Superar cada vez mais meus limites e ser reconhecido pelo meu esforço."

Labronice (2000), por sua vez, acredita que o espírito de competitividade nas pessoas com deficiência física, geralmente é alto, devido à vontade do paratleta de provar sua capacidade para as demais pessoas. Já Benfica, (2012) expressa que:

A realização de movimentos, atividades e exercícios antes considerados impossíveis, a superação de limites fisiológicos e psicológicos, a satisfação pessoal e a oportunidade de novas interações sociais são algumas ações proporcionadas pelo esporte que podem (re)significar positivamente questões individuais do atleta. (BENFICA, 2012, p. 101).

Verifica-se que as paralimpíadas escolares são vistas como uma oportunidade importante para os atletas que têm alguma deficiência, tanto para aqueles que pretendem seguir a carreira de atleta profissional como para aqueles que pretendem apenas melhorar sua qualidade de vida e sua saúde. É possível constatar que os fatores que os motivaram a entrar para o paradesporto ou para a prática esportiva adaptada são mais voltados para inclinações pessoais como o gosto pelo esporte, o desejo de superação e de melhor qualidade de vida, aliados ao papel relevante atribuído à família e aos técnicos. Além disso, as oportunidades oferecidas pelos professores, técnicos e iniciativas de instituições, associações e escolinhas especializadas no esporte adaptado que têm o esporte como possibilidade de participação de alunos com deficiência também contribuíram. Então, essa conjunção de pessoas e iniciativas desempenha um papel importante para os atletas, fazendo com que eles, além da manutenção da saúde, possam experimentar a possibilidade de ser motivo de orgulho para outras pessoas. Essa experiência de valorização parece ser uma vivência muito importante para esses atletas, pois a busca pelo reconhecimento passa a representar grande parte dos seus projetos de futuro. Nesse sentido, verifica-se a relevância da participação nas paralimpíadas escolares na modificação da percepção dos atletas em relação às suas possibilidades e projetos futuros e como oportunidade de serem valorizados e vistos com orgulho pelo meio social.

\title{
Considerações finais
}

O presente estudo permitiu identificar diversos aspectos relacionados à percepção dos atletas em relação às paralimpíadas escolares. Considera-se que os Jogos Paralímpicos de 
2016, sediados pelo Brasil, trouxeram consigo a consolidação do esporte paralímpico no país. É notável a sua contribuição para a popularização das modalidades paralímpicas, além de angariar mais adeptos e inspirar jovens que possuíam algum tipo de deficiência a iniciar uma prática esportiva, a fim de um dia tornarem-se também grandes ídolos mundiais paralímpicos.

Verifica-se que a percepção dos atletas se modifica com a participação nas paralimpíadas escolares. Identificou-se um deslocamento dos projetos de futuro de grande parte dos atletas escolares paralímpicos, a partir de uma possibilidade de fazer algo que goste, de melhorar a qualidade de vida, de poder se superar, entre outros. As paralimpíadas escolares descortinam uma nova possibilidade de vida e reconhecimento, com a possibilidade desse jovem com algum tipo de deficiência se sentir valorizado, de ser motivo de orgulho da família e de ser respeitado socialmente. Essas possibilidades oferecidas pela participação nessa competição têm o potencial de repercutir em toda a vida desses jovens atletas, independentemente de se tornarem profissionais ou não. Mesmo os que não tiverem a intenção de se profissionalizar puderam ter a oportunidade de superar seus limites, de serem escolhidos entre muitos atletas, de participarem da competição de nível escolar de maior dimensão, nacionalmente falando. Estudos longitudinais podem ser realizados visando identificar os impactos da participação em paralimpíadas escolares na vida desses atletas.

\section{Referências}

BALBINOTTI, M. A. A. et al. Qual é o perfil motivacional característico de tenistas infantojuvenis brasileiros. Motriz, Rio Claro, v. 18, n. 4, p. 728-734, 2012.

BALBINOTTI, M. AL. A; CAPAZZOLE, C, J. Motivação a prática regular de atividade física: um estudo de exploratório com praticantes em academia de ginástica. Revista Brasileira de Educação Física e Esporte, São Paulo, v. 22, n. 1, p. 63-80, jan/mar. 2008

BARDIN, L. Análise de conteúdo. Lisboa, Portugal; Edições 70, LDA, 2009

BARRETO, L. C. P. Estudo de caso de abandono esportivo na modalidade de basquetebol. 2008. Monografia (Graduação) - Instituto de Biociências, Universidade Estadual Paulista, Rio Claro, 2008.

BENFICA, D. T. Esporte paralímpico: analisando suas contribuições nas (re)significações do atleta com deficiência. Dissertação (Mestrado) - Universidade Federal de Viçosa, Faculdade de Educação Física, Minas Gerais, 2012.

BRAZUNA, M., R.; CASTRO, E. M. A trajetória do atleta portador de deficiência no esporte adaptado de rendimento. Uma revisão da literatura. Revista Motriz, v. 07, n. 2, p. 115-123, jul./ dez. 2001.

CARDOSO, V. D. O desenvolvimento da carreira esportiva de atletas paraolímpicos no Brasil. 2016. 218 f. Tese (Doutorado em Educação Física) - Universidade Federal do Rio Grande do Sul, Porto Alegre, 2016.

CARDOSO, V. D.; PALMA, L. E.; ZANEllA, A. K. A motivação de pessoas com deficiência para a prática do esporte adaptado. Revista Digital, Buenos Aires, v. 15, 2010. 
COSTA, A. M.; WINCKLER, C. A Educação física e o esporte paralímpico. In.: DE MELLO, M. T.; WINCKLER, C. (Org.) Esporte paralímpico. São Paulo, Atheneu, 2012.

CPB. Comitê Paralímpico Brasileiro. Paralímpiadas escolares. 2015. Disponível em: <http://cpb.org.br.187.38-89-161.groveurl.com/paralimpiadas-escolares/>. Acesso em: 25 out. 2017.

DA COSTA, A. M.; SOUSA, S. B. Educação física e esporte adaptado: história, avanços e retrocessos em relação aos princípios da integração/inclusão e perspectivas para o século XXI. Rev. Bras. Cienc. Esporte, Campinas, v. 25, n. 3, p. 27-42, maio 2004.

FLORENCE, R. B. P. Medalhistas de ouro nas paraolimpíadas de Atenas 2004: Reflexões de suas trajetórias no desporto adaptado. 2009. Tese (Doutorado) - Faculdade de Educação Fisica, Universidade Estadual de Campinas. Campinas, SP, 2009.

GOFFMAN, E. Estigma: notas sobre a manipulação da identidade deteriorada. 4. ed. São Paulo: J. Zahar, 1982.

HAIACHI, M.C., CARDOSO, V.D., REPPOLD FILHO, A.R., GAYA, A. Reflexões sobre a carreira do atleta paraolímpico brasileiro. Revista Ciência e Saúde Coletiva. 2016

ITANI, D. E. Esporte adaptado construído a partir das possibilidades: handebol adaptado. Revista Digital Buenos Aires, a. 10, n. 72, maio, 2004

MELlO, M. T. de.; WINCKLER, C. O esporte paralímpico. São Paulo: Editora Atheneu, 2012.

PALLA, A.C. Atitude de profissionais e alunos universitários sobre a proposta de inclusão. 2001. Dissertação (Mestrado) - Universidade Estadual Paulista, Rio Claro, 2001.

PORTAL BRASIL. Centro de Treinamento Paralímpico inicia suas operações. 2016. Disponível em: <http://www.brasil.gov.br/esporte/2016/05/centro-detreinamentoparalimpico-inicia-suas-operacoes>. Acesso em: 25 out. 2017.

SAITO, S. P. D. Motivos que levam indivíduos portadores de deficiência visual a participarem de atividades desportivas adaptadas de alto nível. Revista Mineira de Educação Física, Viçosa, v. 15, n. 2, p. 20-32, jul. 2007.

SAMPEDRO, L. B. R. Motivação à prática de atividades físicas e esportivas na educação física escolar: um estudo com adolescentes do ensino médio de escolas públicas estaduais da cidade de Porto Alegre-RS. 2012. 137 f. Dissertação (Mestrado) - Universidade Federal do Rio Grande do Sul, Escola de Educação Física, Programa de Pós Graduação em Ciências do Movimento Humano, Porto Alegre, 2012.

SAMULSKI, D.; NOCE, F. Perfil psicológico de atletas paraolímpicos brasileiros. Revista Brasileira de Medicina do Esporte, São Paulo, v. 8, n. 4, p. 157-166, out. 2002.

SILVA, L. H. O. Perfil das pessoas que iniciam na prática do esporte adaptado coletivo na região metropolitana de Goiânia. 2016. 85 f. Monografia (Graduação) - Faculdade de Educação Física e Dança, Universidade Federal de Goiás, Goiânia, 2016. 
TEODORO C M. Esporte adaptado de alto rendimento praticado por pessoas com deficiência: relatos de atletas paraolímpicos. Dissertação (Mestrado) - Universidade Presbiteriana Mackenzie, São Paulo, 2006.

VILLAS BOAS, M. S.; BIM, R.H.; BARIAN, S. H. S. Aspectos motivacionais e benefícios da prática do basquetebol sobre rodas. Revista da Educação Física/UEM, v.14, n.2, p. 7-11, 2003.

WEINBERG, R. S.; GOULD, D. Fundamentos da psicologia do esporte e do exercício. Porto Alegre: Artmed, 2008.

Endereço para correspondência: marianacorrearesende@hotmail.com Mariana Corrêa de Resende Universidade Federal de São João Del Rei, Centro Científico, Departamento das Psicologias. Praça Dom Helvécio, 74

Fábricas

36307-024 - Sao Joao Del Rei, MG - Brasil 